\title{
Identification of novel proteins affected by rotenone in mitochondria of dopaminergic cells Jinghua Jin ${ }^{1,2}$, Jeanne Davis ${ }^{1}$, David Zhu ${ }^{1}$, Daniel T Kashima ${ }^{1}$, Marc Leroueil ${ }^{1}$, Catherine Pan ${ }^{1}$, Kathleen S Montine ${ }^{1}$ and Jing Zhang*1
}

Address: ${ }^{1}$ Department of Pathology, University of Washington School of Medicine, Seattle, WA, USA and ${ }^{2}$ Department of Neurobiology, Zhejiang University School of Medicine, Hangzhou, Zhejiang, China

Email: Jinghua Jin - jhjin@zju.edu.cn; Jeanne Davis - jeanne3@u.washington.edu; David Zhu - djzhu@u.washington.edu; Daniel T Kashima - kashid@u.washington.edu; Marc Leroueil - lerouemm@whitman.edu; Catherine Pan - panc@u.washington.edu; Kathleen S Montine - kmontine@u.washington.edu; Jing Zhang* - zhangj@u.washington.edu

* Corresponding author

Published: 16 August 2007

BMC Neuroscience 2007, 8:67 doi:10.1/86/147|-2202-8-67
Received: 18 January 2007

Accepted: 16 August 2007

This article is available from: http://www.biomedcentral.com/I47I-2202/8/67

(C) 2007 Jin et al; licensee BioMed Central Ltd.

This is an Open Access article distributed under the terms of the Creative Commons Attribution License (http://creativecommons.org/licenses/by/2.0), which permits unrestricted use, distribution, and reproduction in any medium, provided the original work is properly cited.

\begin{abstract}
Background: Many studies have shown that mitochondrial dysfunction, complex I inhibition in particular, is involved in the pathogenesis of Parkinson's disease (PD). Rotenone, a specific inhibitor of mitochondrial complex I, has been shown to produce neurodegeneration in rats as well as in many cellular models that closely resemble PD. However, the mechanisms through which complex I dysfunction might produce neurotoxicity are as yet unknown. A comprehensive analysis of the mitochondrial protein expression profile affected by rotenone can provide important insight into the role of mitochondrial dysfunction in PD.

Results: Here, we present our findings using a recently developed proteomic technology called SILAC (stable isotope labeling by amino acids in cell culture) combined with polyacrylamide gel electrophoresis and liquid chromatography-tandem mass spectrometry to compare the mitochondrial protein profiles of MES cells (a dopaminergic cell line) exposed to rotenone versus control. We identified 1722 proteins, 950 of which are already designated as mitochondrial proteins based on database search. Among these 950 mitochondrial proteins, 110 displayed significant changes in relative abundance after rotenone treatment. Five of these selected proteins were further validated for their cellular location and/or treatment effect of rotenone. Among them, two were confirmed by confocal microscopy for mitochondrial localization and three were confirmed by Western blotting (WB) for their regulation by rotenone.
\end{abstract}

Conclusion: Our findings represent the first report of these mitochondrial proteins affected by rotenone; further characterization of these proteins may shed more light on PD pathogenesis.

\section{Background}

Parkinson's disease (PD) is the second most common neurodegenerative disorder after Alzheimer's disease (AD) $[1,2]$. Pathological characteristics of PD include the progressive and relatively selective loss of nigrostriatal dopaminergic neurons and the deposit of protein aggregates in the remaining neurons called Lewy bodies (LBs) [3]. The mechanisms underlying PD development and LB formation are not fully characterized, although increasing evidence suggests that mitochondrial dysfunction, oxida- 
tive damage, excitotoxicity, and inflammation are contributing factors $[4,5]$. Of these potential mechanisms, mitochondrial dysfunction has been studied most extensively. It has been reported by many groups that there is a partial inhibition (20-40\%) of respiratory chain complex I activity in PD patients [6-8]. The importance of complex I inhibition is further substantiated by the fact that mitochondrial toxicants, e.g. 1-methyl-4-phenyl-1,2,3,6-tetrahydropyridine (MPTP) [9], a contaminant of a synthetic heroin, and rotenone [10], a plant-derived pesticide, recapitulate parkinsonism in animals that closely resembles human PD.

Rotenone is a lipophilic compound that freely crosses cell membranes and accesses cytoplasm and mitochondria. Its application in PD research has grown exponentially over the last few years largely due to the discovery of its ability to produce many features of PD in rats, including development of $\alpha$-synuclein-positive cytoplasmic inclusions similar to LBs in human PD in the remaining nigral neurons [11]. In vitro, rotenone appears to produce many cellular effects, e.g. caspase 3 activation (and apoptosis), change in mitochondrial membrane potential, accumulation and aggregation of $\alpha$-synuclein and ubiquitin, oxidative damage, and endoplasmic reticulum stress [12-16].
Although many of the findings observed in rotenone induced cellular and animal models of PD are also present in the brains of patients with $\mathrm{PD}$, the precise mechanisms through which complex I dysfunction might produce neurotoxicity are as yet unknown. One of the major issues centers on what happens after complex I is inhibited by rotenone. While this question has been approached thus far by testing one hypothesis at a time, the rapidly emerging field of proteomics offers great potential to globally identifying and characterizing mitochondrial proteins involved in these processes in a nonbiased manner. Indeed, in the last few years, we, as well as others, have already started to utilize this technology to extensively characterize the proteins interacting with $\alpha$-synuclein [17] and DJ-1 [18,19].

Here, we employed a recently introduced proteomics technology called SILAC (stable isotope labeling by amino acids in cell culture) [20] combined with MudPIT (multidimensional protein identification technology) [21], including SDS-PAGE (polyacrylamide gel electrophoresis) and liquid chromatography (LC), and mass spectrometry (MS) for protein identification as well as quantification in dopaminergic (DAergic) MES cells exposed to rotenone vs. controls. MES cells are a DAergic

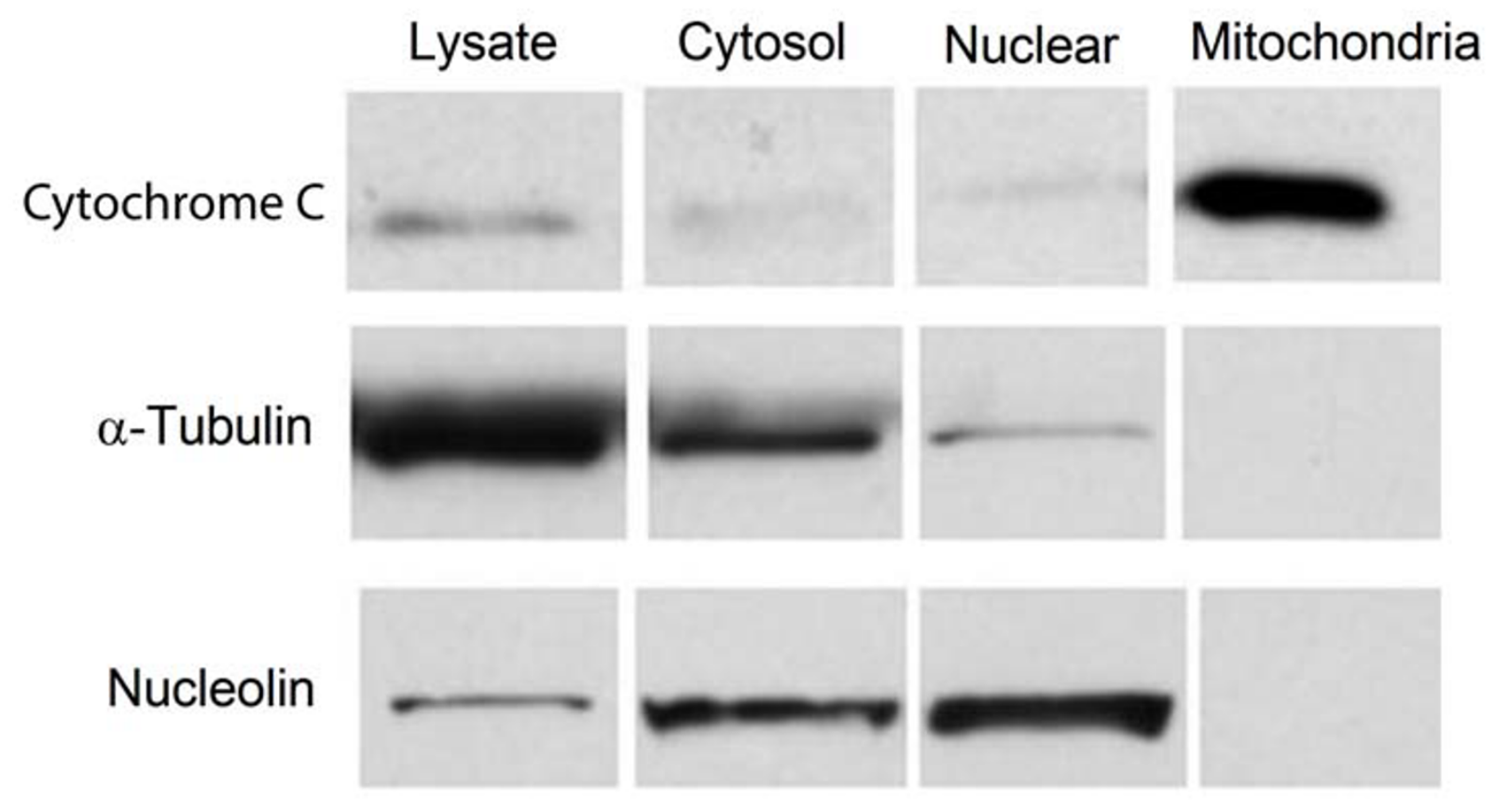

Figure I

Purity evaluation of isolated mitochondria by WB. Equal amounts of protein (20 $\mu \mathrm{g}$ for cytochrome $\mathrm{C}$ and nucleolin, 5 $\mu \mathrm{g}$ for tubulin) were loaded onto an 8-16\% SDS-PAGE and analyzed by WB with indicated antibodies against marker proteins from mitochondria, cytosol, or nucleus. Antibodies against $\alpha$-tubulin and nucleolin were used as markers for cytosolic and nuclear fractions, respectively. Antibodies directed against cytochrome $C$ were used as markers for mitochondrial fraction. 
cell line that have been demonstrated to form cytoplasmic LB-like inclusions after rotenone treatment [17]. In this study, however, only mitochondrial proteins, isolated by sucrose-gradient centrifugation, were studied. A total of 1864 proteins were identified with quantitative proteomics analysis; of those, 1722 proteins were identified as mitochondrial protein or mitochondria-associated proteins and 110 of which displayed significant changes in relative abundance after rotenone treatment. A subset of these proteins was further validated by confocal microscopy and WB to confirm their mitochondrial localization as well as regulation by rotenone. As none of these proteins have been associated with rotenone toxicity previously, our findings represent the first report of these novel mitochondrial proteins affected by rotenone.

\section{Results Evaluation of the purity of mitochondrial isolation}

To minimize false positive results in identifying mitochondrial proteins, it is critical to isolate mitochondria with minimal contamination of other organelles. To achieve this goal, we first used an optimized purification procedure, allowing for production of high-purity mitochondria from MES cells. This procedure involved three differential centrifugations followed by sucrose density gradient centrifugation using three sucrose densities. The purity of mitochondria was assessed by following the relative distribution of various cellular markers, including cytochrome $\mathrm{C}$ for mitochondria, $\alpha$-tubulin for cytosol, and nucleolin for nucleus. The results, shown in Figure 1, demonstrate that mitochondrial protein cytochrome $\mathrm{C}$ was highly enriched in the purified mitochondrial fraction while the cytosolic protein $\alpha$-tubulin and nuclear protein nucleolin were decreased to near or below the limit of detection in the mitochondrial fraction.

\section{Identification of mitochondrial proteome in MES cells}

Pure mitochondrial preparations were isolated from combined extracts of cells exposed to $20 \mathrm{nM}$ rotenone (in L$\left[{ }^{13} \mathrm{C}_{6}\right] \mathrm{Arg}$ ) or vehicle (in $\mathrm{L}-\left[{ }^{12} \mathrm{C}_{6}\right] \mathrm{Arg}$ ) for 3 days as described previously [22]. SDS-PAGE combined with twodimensional LC followed by tandem MS (MS/MS) analysis identified a total of 1864 proteins (error rate < 0.05) with more than 2 peptides [see Additional file 1]. These results were a combination of two independent experiments. Among the identified proteins, 228 (12.2\%) were previously identified as mitochondrial proteins based on the protein names in the database. One obvious question is how many of the remaining proteins were also mitochondrial proteins? To address this, we searched all the identified proteins against the most comprehensive mitochondrial proteome database, MitoP2, which combines information regarding the genetic, functional and pathogenetic aspects of nuclear-encoded mitochondrial proteins. Besides data for proteins known to be mitochondrial in origin, MitoP2 also provides information about putative mitochondrial proteins identified by homology search tools. Each protein entry is annotated with function, chromosomal localization, subcellular localization, homologs and associated confidence values, GO (Gene Ontology) number, applicable OMIM (Online Mendelian Inheritance in Man) [23], literature references, and cross-references to external databases. Our search results showed that 950 out of 1864 (including 228 proteins that have been previously identified as mitochondrial) proteins were found in MitoP2 [see Additional file 1]. The remaining proteins were further searched against SWISS-Prot database http://www.expasy.org/sprot/ for subcellular localization or function. 142 proteins were "localized" to cytoplasm, nucleus, ER, golgi, lysosome, microsome, peroxisome or synaptosome and thus considered likely contaminants. The remaining 772 proteins showed unknown functions or unknown localization.

\section{Proteins affected by rotenone treatment}

We, as well as others, have established that rotenone not only induces cell death but also replicates many cellular processes, e.g. mitochondrial dysfunction and oxidative stress $[10,24]$, which occur in human PD. Like our previous studies $[17,18,25]$, MES cells treated with rotenone at $20 \mathrm{nM}$ demonstrated significant cellular toxicity, losing about $50 \%$ of cells by day 3 after the treatment started (Trypan blue assay and MTT assay; data not shown). We used 3-day rotenone treatment regimen because our early investigations have indicated that MES cells treated with rotenone for three days demonstrated cytoplasmic LB-like inclusions immunoreactive to anti- $\alpha$-synuclein [17], a phenomenon not seen in cells exposed for 1 or 2 days. Quantitative analysis of the mitochondrial protein profiles identified 311 proteins that displayed changes in relative abundance in MES cells treated with rotenone vs. controls, using a 2-fold increase or decrease over controls as significant. The results were expressed as combined ASAPRatio (average ratio \pm SE) obtained from two independent experiments. By this criterion, a total of 156 and 155 proteins showed a significant increase or decrease, respectively, after rotenone treatment. Of the 311 proteins, 110 could be found in the MitoP2 database. These proteins are listed in Table 1 where those that have been implicated in the cellular processes relevant to neurodegenerative disease or rotenone pathogenesis are noted. Figure 2 shows a pie chart summarizing the functional categories of the 110 proteins. Major classes of proteins included those related to transport, metabolism and signal transduction. Notably, almost a third of proteins listed in Table 1 are without known function. 


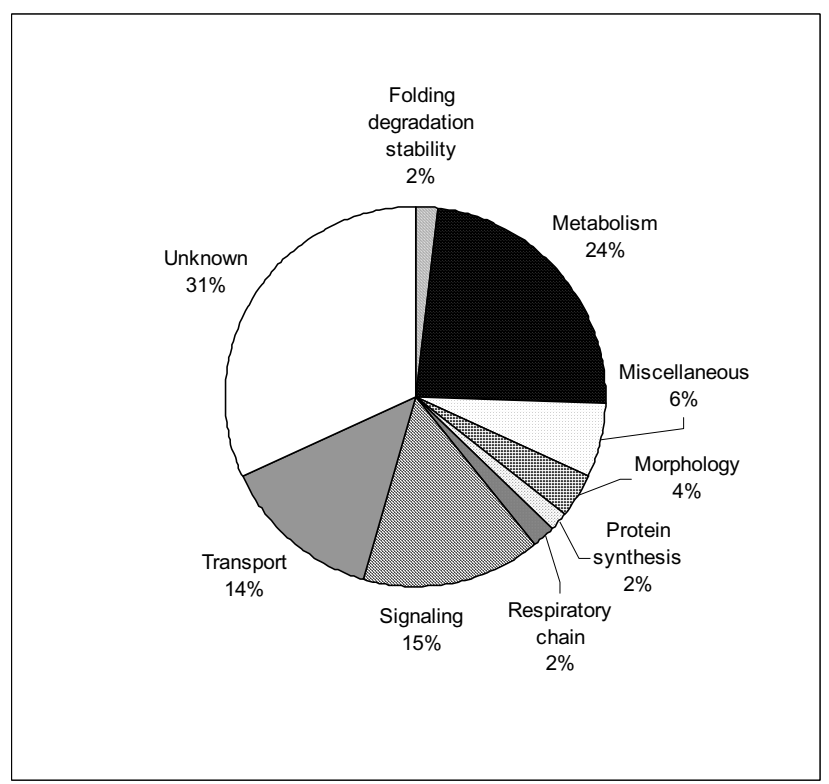

\section{Figure 2}

Functional classification of mitochondrial proteins with relative abundance changes after rotenone treatment. 110 proteins identified in the mitochondrial database MitoP2 and having 2 -fold relative abundance changes after rotenone treatment were classified into the following categories: folding degradation stability, metabolism, morphology, respiratory chain, protein synthesis, signaling, transport, miscellaneous, and unknown functions. For a protein with multiple functions, it is assigned to the one that is best known. While this chart reflects the group as a whole, the distribution was the same regardless of response to rotenone. Functional classification of proteins for each of the four groups shown in Table I (ASAPRatio $=0, \geq 2.0, \leq 0.5$, or $=999)$ resulted in distributions that were not different from each other ( $\chi^{2}$ had $P>0.05$ for the four groups).

\section{Validation of a subset of mitochondrial proteins affected by rotenone}

While all proteins listed in Table 1 are considered mitochondrial proteins based on the MitoP2 database, not all of them have been validated biochemically or morphologically. Also, as proteomics identification of candidate proteins can be wrong owing to current incorrect or incomplete database, candidate proteins need to be validated with alternative means not only for their identification but also for their quantification. It is obviously impractical to validate all the proteins listed in Table 1. Thus, we chose 5 proteins from Table 1 for their mitochondrial localization as well as quantitative regulation by rotenone; these proteins are: mitogen activated protein kinase kinase 2 (MAP2K2), sacsin, sonic hedgehog $(\mathrm{SHH})$, sorting nexin 1 (SNX1), and vesicle-associated membrane protein 3 (VAMP3). This selection was based on the following rationale: 1) all of these proteins were identified by multiple peptides and also have commercially available antibodies; 2) the selected proteins displayed quantitative changes in response to rotenone and were thus more likely to be biologically interesting and less likely to be nonspecific contaminating proteins; and 3 ) these proteins are involved in cellular processes that might be important in PD pathogenesis, even though none of them have been linked to PD directly to date.

To confirm mitochondrial localization of these proteins, we performed double immunostaining of each of the candidates along with cytochrome $\mathrm{C}$, followed by confocal analysis. Of the antibodies tested, only two ( $\mathrm{SHH}$ and SNX1), shown in Figure 3, demonstrated enough sensitivity and specificity for immunocytochemistry. SHH was localized to the cytoplasm as well as in the mitochondria but excluded from the nuclei while SNX1 was diffusely localized in the cytoplasm, mitochondria and nuclei. Notably, although the staining patterns of these proteins were different from each other, both of them co-localized with cytochrome $\mathrm{C}$ to some extent in the mitochondria. It should be emphasized that it is not surprising to see the presence of these proteins in other cellular compartments, as neither of the candidates is synthesized within the mitochondria.

To validate quantitative proteomics results, three sets of mitochondrial proteins were isolated from three independent samples. The cytosolic fraction was also included for comparison. The results of these experiments are summarized in Table 2. In the mitochondrial fraction, sacsin and SNX1 levels were significantly decreased by rotenone exposure, while VAMP3 levels were significantly increased. These results were in good agreement with our quantitative proteomics results (Table 2). Sacsin and VAMP3 were also present in the cytosolic fraction of both rotenone and vehicle-treated cells, while SNX1 was not detectable (Figure 4). We did not observe any significant change in the relative abundance of either sacsin or VAMP3 in the cytosolic fraction following rotenone exposure. Antibody against MAP2K2 was not sensitive/specific enough when assessed by WB. In the case of SHH antibody, it responded to immunostaining but showed multiple bands in immunoblotting, which could be biological but made it impossible to compare with the proteomic results. Representative WB results for the other three proteins are shown in Figure 4.

\section{Discussion}

In this study, we combined SILAC labeling, MudPIT separation of protein/peptide, including SDS-PAGE, and tandem MS to characterize the mitochondrial proteome of MES cells as well as the alterations in the mitochondrial proteome in the presence of rotenone. Several major findings have been found from this investigation, including: 
Table I: Mitochondrial proteins affected by rotenone treatment

\begin{tabular}{|c|c|c|c|}
\hline \multicolumn{4}{|c|}{ Increased $\geq$ two-fold after rotenone treatment } \\
\hline protein & Description & ASAPRatio* & $\begin{array}{l}\text { Ref(s) for relevance to } \\
\text { neurodegenerative disease }\end{array}$ \\
\hline IPI003।9790 & Dnaj (Hsp40) homolog, subfamily C, member 7 & 0 & \\
\hline IPI0033|385 & MdjII & & \\
\hline IPI0037I053 & Similar to dnaj (Hsp40) homolog, subfamily C, member 7 & & \\
\hline IPI00| 28647 & Crumbs-like protein I precursor & 0 & \\
\hline IPI00204778 (IPI00| 29395) & Large neutral amino acids transporter small, subunit I & 0 & \\
\hline IPI00331577 & Solute carrier family 7 (Cationic amino acid transporter $y+$ system) member 5 & & \\
\hline IPI00223004 & Peroxisomal CA-dependent solute carrier homolog & 0 & \\
\hline IPI00208799 & Solute carrier organic anion transporter family member IA5 & 0 & \\
\hline IPI00|30878 & Voltage-dependent T-type calcium channel alpha-IH subunit & 0 & \\
\hline IPI003883।I & Ensembl_locations(Chr-bp):10-14622136 & & \\
\hline IPI00|89595 & Voltage-dependent T-type calcium channel alpha-IH subunit & & \\
\hline IPI002। 3584 & Alanine - glyoxylate aminotransferase 2 mitochondrial precursor & 0 & \\
\hline IPI00365283 & Similar to capping protein beta subunit, isoform 2 & 0 & \\
\hline IPI00406800 & Splice isoform I of P47757 F-actin capping protein beta subunit & & \\
\hline IPI00II 3992 & GDP-mannose pyrophosphorylase B homolog & 0 & \\
\hline IPI00I53603 & $28 \mathrm{~S}$ ribosomal protein $s \mid 8 \mathrm{c}$, mitochondrial precursor & 0 & \\
\hline IPI00372556 & Similar to NG26 & 0 & \\
\hline IPI00I30339 & Protein BAT5 & & \\
\hline IPI00|23I38 & Leucyl-trna synthetase & 0 & \\
\hline IPI00II6966 & Asparagine synthetase & 0 & \\
\hline IPI00406634 & Ensembl_locations(Chr-bp):8-124923273 & 0 & [48] \\
\hline IPI00|70| 28 (IPI00327|08) & Paraplegin & & \\
\hline IPI00|34390 & Microsomal dipeptidase precursor & 0 & \\
\hline IPI00200392 & SMHS2 & 0 & \\
\hline IPI00|77|83 & RIKEN cDNA 4833427E09 gene & & \\
\hline IPI00II69|3 & Laminin alpha- 5 chain precursor & 0 & \\
\hline $\begin{array}{l}\text { IPI0033I } 507 \\
\text { (IPI003255I7) }\end{array}$ & Cullin homolog 5 & 0 & \\
\hline IPI00|35708 & Dual specificity mitogen-activated protein kinase kinase 2 & 0 & [49] \\
\hline IPI00407256 & Mitogen activated protein kinase kinase 2 & & \\
\hline IPI0023|33| & Dual specificity mitogen-activated protein kinase kinase 2 & & \\
\hline IPI00| 18384 & 14-3-3 protein epsilon & 0 & \\
\hline \multicolumn{4}{|l|}{ (IPI00325I35) } \\
\hline IPI00309516 & Hedgehog-interacting protein & 0 & \\
\hline IPI00318010 & Polycystic kidney disease I-like 2 & 0 & \\
\hline IPI00368473 & Nuclear mitotic apparatus protein I & 0 & \\
\hline IPI0037|74| & Similar to zinc finger protein TZF-L & 0 & \\
\hline IPI00408I82 & Tmc3 protein & 0 & \\
\hline IPI00222063 & Weakly similar to hypothetical $71.7 \mathrm{kda}$ protein & 0 & \\
\hline IPI00222264 & HRIHFB2003 protein homolog & 0 & \\
\hline IPI00366079 & Similar to expressed sequence AL02264I & 0.02 & \\
\hline IPI00I630II & Thioredoxin domain containing protein 5 precursor & & \\
\hline IPI00396730 & Growth differentiation factor 10 & $0.1 \pm 0.02$ & \\
\hline IPI00I65799 & UBX domain-containing protein 2 & $0.12 \pm 0.1$ & \\
\hline IPI0037|952 & Similar to RIKEN cDNA $13000 \mid 3 \mathrm{G} / 2$ & & \\
\hline IPI00I 29470 & Ran gtpase-activating protein I & $0.13 \pm 0.03$ & \\
\hline IPI00319167 & Hydrocephalus inducing & $0.13 \pm 0.05$ & \\
\hline IPI003I0I28 & Tissue inhibitor of metalloproteinase 2 & $0.15 \pm 0.02$ & \\
\hline IPI00|3280I & Glucagon-like peptide I receptor precursor & $0.22 \pm 0.05$ & \\
\hline IPI003।I576 & Testis expressed gene 10 & $0.24 \pm 0.08$ & \\
\hline IPI00400। 37 & RIKEN cDNA I2000I IN24 & $0.27 \pm 0.05$ & \\
\hline IPI00403336 & MKIAA0567 protein & & \\
\hline IPI00II 7657 & Dynamin-like $120 \mathrm{kda}$ protein, mitochondrial precursor & & \\
\hline IPI0034| 975 & RIKEN cDNA 6430598A04 gene & $0.27 \pm 0.09$ & \\
\hline IPI003I7309 & Annexin A5 & $0.27 \pm 0.12$ & [50] \\
\hline
\end{tabular}


Table I: Mitochondrial proteins affected by rotenone treatment (Continued)

\begin{tabular}{|c|c|c|c|}
\hline IPI00231954 & 6-phosphofructokinase, type C & $0.31 \pm 0.06$ & \\
\hline IPI00II 3824 & Basement membrane-specific heparan sulfate proteoglycan core protein precursor & $0.33 \pm 0.09$ & \\
\hline IPI00I32276 (IPI0021097I) & Vesicle-associated membrane protein 3 & $0.34 \pm 0.07$ & \\
\hline IPI002I0089 & Voltage-gated sodium channel & $0.35 \pm 0.06$ & [5I] \\
\hline IPI00II 0560 & Talin I & $0.36 \pm 0.06$ & \\
\hline IPI003620I4 & similar to talin & & \\
\hline IPI00I9II07 & Similar to mitochondrial ribosomal protein S2I & $0.37 \pm 0.16$ & \\
\hline IPI0039|28I & Ensembl_locations(Chr-bp):2-190609002 & & \\
\hline IPI00I 27069 & Sideroflexin 2 & $0.38 \pm 0.05$ & [52] \\
\hline IPI00400079 & Splice isoform I of Q9JLT4 Thioredoxin reductase 2, mitochondrial precursor & $0.4 \pm 0.19$ & \\
\hline IPI00I 24699 & Thioredoxin reductase 2 & & \\
\hline IPI00403407 & $\begin{array}{l}\text { Adult male stomach cDNA, RIKEN full-length enriched library, clone:2210009012 } \\
\text { product:thioredoxin reductase } 2 \text {, full insert sequence }\end{array}$ & & \\
\hline IPI00350590 & Splice isoform 4 of Q9JLT4 Thioredoxin reductase 2, mitochondrial precursor & & \\
\hline IPI00207072 & NADH-ubiquinone oxidoreductase $13 \mathrm{kda}-\mathrm{A}$ subunit, mitochondrial precursor & $0.41 \pm 0.13$ & \\
\hline IPI00330862 & Villin 2 & $0.42 \pm 0.07$ & \\
\hline IPI00III460 & Williams-Beuren syndrome chromosome region 16 protein homolog & $0.46 \pm 0.12$ & \\
\hline IPI00I89798 & Similar to Williams-Beuren syndrome chromosome region 16 homolog & & \\
\hline IPI00II 2935 & Serine hydroxymethyltransferase & $0.47 \pm 0.06$ & [53] \\
\hline IPI00I3I577 & Heme oxygenase I & $0.47 \pm 0.12$ & [54] \\
\hline IPI00I 77038 & Actin-like protein 2 & $0.47 \pm 0.17$ & \\
\hline IPI004000I 2 & Similar to Actin-like protein 2 (Actin-related protein 2) & & \\
\hline IPI00362072 & Similar to actin-related protein 2 & & \\
\hline IPI00364385 & Similar to RIKEN cDNA 5730406115 & $0.5 \pm 0.19$ & \\
\hline IPI00228236 & Microsomal signal peptidase $25 \mathrm{kda}$ subunit & & \\
\hline
\end{tabular}

\section{Decreased $\geq$ two-fold after rotenone treatment}

\begin{tabular}{|c|c|c|}
\hline IPI002I 2082 & Ensembl_locations(Chr-bp):I-I53887|03 & $2.03 \pm 0.62$ \\
\hline IPI00368435 & Similar to Ten-m4 & \\
\hline IPI00I57497 & Ten-m4 & \\
\hline IPI0035।867 & Odd Ozlten-m homolog 4 & \\
\hline IPI002I0503 & Long-chain-fatty-acid - coa ligase 4 & $2.04 \pm 0.44$ \\
\hline $\begin{array}{l}\text { IPI00403I80 } \\
\text { (IPI00378474) }\end{array}$ & Similar to mitochondrial isoleucine trna synthetase & $2.06 \pm 0.22$ \\
\hline IPI00408243 & Similar to single-stranded DNA binding protein & $2.07 \pm 0.19$ \\
\hline IPI00I 24980 & Prolactin regulatory element-binding protein & $2.09 \pm 0.48$ \\
\hline IPI00229040 & Retinol dehydrogenase 13 & $2.15 \pm 2.41$ \\
\hline IPI00I98369 & Sorting nexin I & $2.21 \pm 0.6$ \\
\hline IPI00|2544I & Sorting nexin I & \\
\hline$|\mathrm{PI} 00| 24 \mid 20$ & Sacsin & $2.26 \pm 0.38$ \\
\hline IPI003730I2 & Similar to sacsin & \\
\hline IPI00364603 & Similar to RNA-binding protein EWS & $2.33 \pm 0.31$ \\
\hline IPI00I9I745 & Similar to coproporphyrinogen oxidase & $2.38 \pm 0.41$ \\
\hline $\begin{array}{l}\text { IPI00I } 92034 \\
(\text { IPI00I I 4375) }\end{array}$ & Dihydropyrimidinase related protein-2 & $2.46 \pm 0.44$ \\
\hline IPI00285485 & Protein kinase C-binding protein NELL2 precursor & $2.57 \pm 0.61$ \\
\hline IPI00I36067 & Jagged 2 precursor & $2.73 \pm 0.46$ \\
\hline IPI00365920 & Jagged 2 & \\
\hline IPI003III509 & Aladin & $2.9 \pm 0.64$ \\
\hline IPI00205|82 & Interleukin-6 receptor alpha chain precursor & $3.03 \pm 0.48$ \\
\hline IPI00206288 & interleukin 6 receptor & \\
\hline IPI00344360 & Transcription termination factor, mitochondrial & $4 \pm 1.42$ \\
\hline IPI00370029 & Similar to NG28 & $4.43 \pm 0.97$ \\
\hline IPI00378753 & Similar to aminopeptidase $\mathrm{N}$ & $4.68 \pm 0.99$ \\
\hline IPI00405386 & T-complex protein $10 \mathrm{a}$ & $5.36 \pm 0.87$ \\
\hline IPI00230453 & Similar to VIP36-like protein precursor (Lectin, mannose-binding 2-like) & $5.45 \pm 0.6$ \\
\hline IPI00357887 & Similar to lectin, mannose-binding 2-like & \\
\hline IPI00|233|4 & Sonic hedgehog protein precursor & $5.47 \pm 0.98$ \\
\hline $\begin{array}{l}\text { IPI00I96054 } \\
\text { (IPI00I25256) }\end{array}$ & C-C chemokine receptor type 2 & $6.4 \pm 1.67$ \\
\hline IPI00353420 & Cytoskeletal protein & $7.56 \pm 1.41$ \\
\hline
\end{tabular}


Table I: Mitochondrial proteins affected by rotenone treatment (Continued)

\begin{tabular}{|c|c|c|c|}
\hline IPI00388450 & Protein tyrosine phosphatase, receptor type, $\mathrm{U}$ & $8 \pm 1.03$ & \\
\hline IPI00338565 & Mutant fibrillin-I & $8.39 \pm 2.97$ & \\
\hline IPI00I 22438 & Fibrillin I precursor & & \\
\hline IPI00229434 & Apoptosis stimulating of $\mathrm{p} 53$ protein 2 & $\begin{array}{l}38.26 \pm \\
2.99\end{array}$ & \\
\hline IPI00269076 & Adenylate kinase 2 & 999 & \\
\hline $\begin{array}{l}\text { IPI002 | } 4038 \\
(\text { IPI00 I I } 8120)\end{array}$ & Myosin Va & 999 & \\
\hline IPI00393437 & Ensembl_locations(Chr-bp):8-80002855 & & \\
\hline IPI0040588| & Ensembl_locations(Chr-bp):9-776II 564 & & \\
\hline IPI00331016 & Similar to SEC24 related gene family, member B & 999 & \\
\hline IPI00372727 & Similar to Protein transport protein Sec24B (SEC24-related protein B) & & \\
\hline IPI00309437 & ALDR protein & 999 & \\
\hline IPI00387535 & Fatty acid coenzyme A ligase, long chain 3 & 999 & \\
\hline IPI00I69772 & Long-chain-fatty-acid - coA ligase 3 & & \\
\hline IPI00330207 & Splicing factor 3B subunit I & 999 & [57] \\
\hline IPI00366952 & Splicing factor 3b, subunit I, I55kd & & \\
\hline IPI00II8235 & Mitochondrial $60 \mathrm{~S}$ ribosomal protein $\mathrm{L} 3$ & 999 & \\
\hline IPI00II 5094 & [3-methyl-2-oxobutanoate dehydrogenase [lipoamide]] kinase, mitochondrial precursor & 999 & \\
\hline IPI00409229 & Ensembl_locations(Chr-bp):7-I20047962 & & \\
\hline IPI00204344 & [3-methyl-2-oxobutanoate dehydrogenase [lipoamide]] kinase, mitochondrial precursor & & \\
\hline IPI00324I80 & Breast cancer type 2 susceptibility protein homolog & 999 & \\
\hline IPI003666I4 & Breast cancer susceptibility protein BRCA2 & & \\
\hline IPI00II802I & Gtrgeo22 & 999 & \\
\hline IPI003I3998 & Sulfide:quinone oxidoreductase, mitochondrial precursor & 999 & \\
\hline IPI00357889 & Similar to $28 \mathrm{~S}$ ribosomal protein 59 , mitochondrial precursor (MRP-S9) & 999 & \\
\hline IPI00I 32700 & $39 S$ ribosomal protein $\mathrm{L} 35$, mitochondrial precursor & 999 & \\
\hline IPI00I89766 & Membrane associated progesterone receptor component I & 999 & \\
\hline IPI00208648 & Disks large-associated protein 2 & 999 & \\
\hline IPI00II79|2 & Semaphorin 5B precursor & 999 & \\
\hline IPI00400269 & Hypothetical protein & & \\
\hline IPI00365296 & $\begin{array}{l}\text { Similar to sema domain, seven thrombospondin repeats (type I and type I-like), transmembrane } \\
\text { domain (TM) and short cytoplasmic domain, (semaphorin) } 5 B\end{array}$ & & \\
\hline IPI00403907 & $\begin{array}{l}\text { Sema domain, seven thrombospondin repeats (type I and type I-like), transmembrane domain } \\
\text { (TM) and short cytoplasmic domain }\end{array}$ & & \\
\hline$|\mathrm{PI} 00| 27|3|$ & Osal nuclear protein & 999 & \\
\hline IPI00II $32 \mid 4$ & Ubiquitin carboxyl-terminal hydrolase 5 & 999 & [58] \\
\hline IPI00II8333 & RWI protein & 999 & \\
\hline IPI00362105 & Similar to proteasome 26 S ATPase subunit 6 & 999 & \\
\hline IPI00I2597I & $26 \mathrm{~S}$ protease regulatory subunit $\mathrm{SIOB}$ & & \\
\hline IPI0023। 757 & Proteasome (prosome, macropain) subunit, alpha type 2 & 999 & [59] \\
\hline IPI00404II7 & Proteasome subunit alpha type 2 & & \\
\hline IPI003I8970 & Proteasome (Prosome, macropain) subunit, alpha type 2 & & \\
\hline IPI00337930 & RIKEN cDNA 4930432B04 & 999 & \\
\hline IPI00203604 & Brain protein 44-like protein & 999 & \\
\hline IPI0040296I & Ensembl_locations(Chr-bp):I2-106426680 & & \\
\hline IPI00I 24292 & Brain protein 44 -like protein & & \\
\hline IPI00406403 & Ensembl_locations(Chr-bp):Un_random_NT_060620-56 II & 999 & \\
\hline IPI0038I837 & similar to putative pheromone receptor & & \\
\hline IPI00372549 & Similar to MHC class I cell surface glycoprotein & 999 & \\
\hline IPI0036775I & Similar to pecanex I & 999 & \\
\hline IPI00365997 & Similar to PHD finger protein 2 & 999 & \\
\hline IPI00| | 4424 & RIKEN cDNA D930036F22 gene & 999 & \\
\hline IPI00326|4| & Augmenter of liver regeneration & 999 & \\
\hline IPI00|9|045 & Similar to zinc finger protein 296 & 999 & \\
\hline IPI002I0I83 & Nuclear receptor binding factor-I & 999 & \\
\hline
\end{tabular}

IPI: International protein index. ASAP Ratio: Automated Statistical Analysis of Protein abundance ratio. The results are expressed as $12 \mathrm{C}$ (DMSO)/13 C (Rotenone). *: Ratio was expressed as 0 and 999 when only the ${ }^{13} \mathrm{C}$ - and ${ }^{12} \mathrm{C}$-labeled peptides were found, respectively, in the sample. Proteins sharing the same peptides but with different protein identification numbers are listed in one cell. 

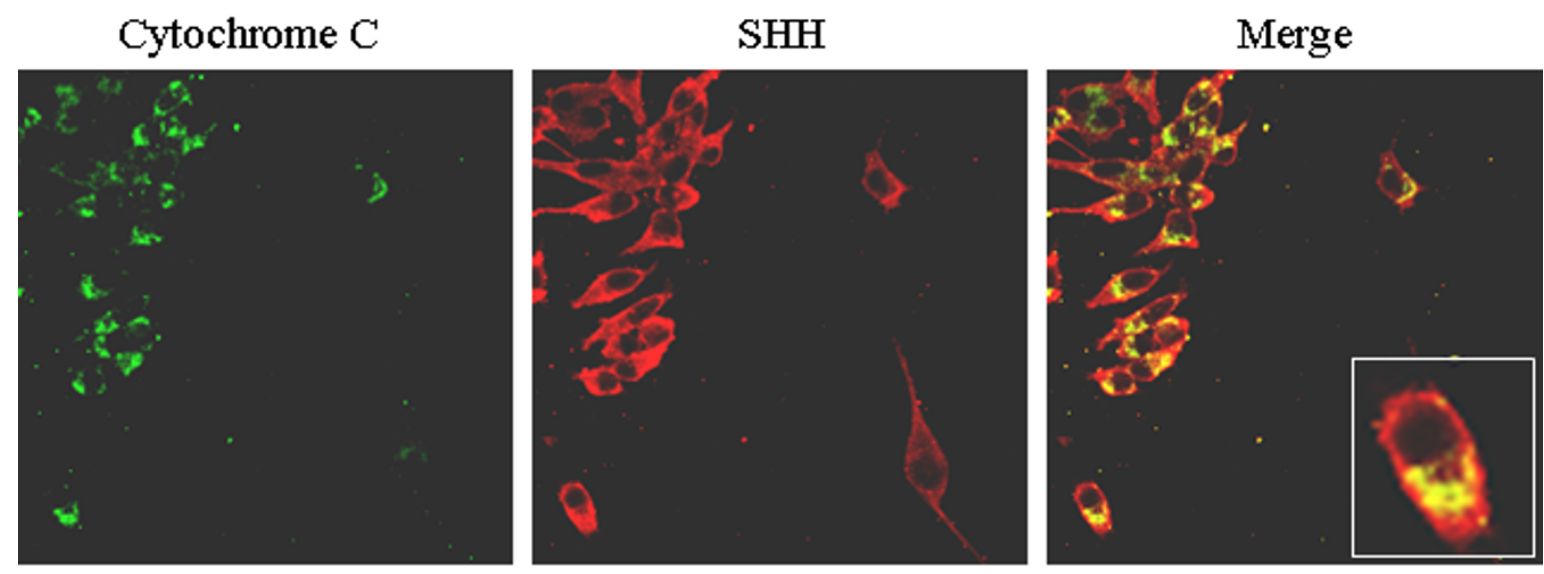

\section{Cytochrome C}

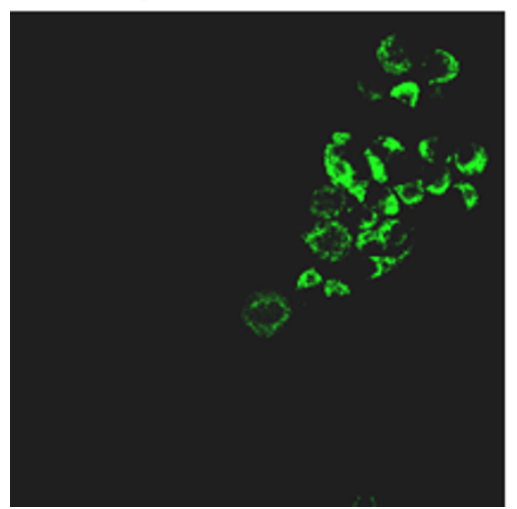

SNX1

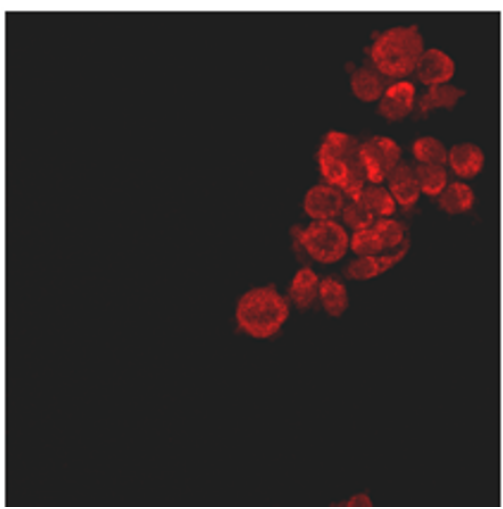

\section{Merge}

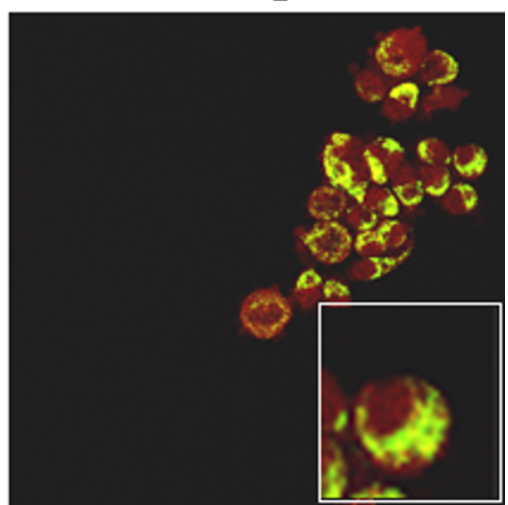

Figure 3

Co-localization of SHH and SNXI with cytochrome C in MES cells. MES cells were fixed and double stained with antibodies against cytochome $\mathrm{C}$ (green) and SHH or SNXI (red). The images were visualized with a confocal microscope. Merged images are shown in yellow when two antibodies are co-localized.

Table 2: Summary of validation by WB and immunolocalization

\begin{tabular}{|c|c|c|c|c|c|c|}
\hline Protein & IPI & Function & ASAP Ratio & WB of mitochondria & WB of cytosol & Co-localized with cyt C* \\
\hline MAP2K2 & $\begin{array}{l}00135708 \\
00407256 \\
0023|33|\end{array}$ & Signaling & 0 & Low sensitivity & Low sensitivity & N/A \\
\hline Sacsin & $\begin{array}{l}00124120 \\
00373012\end{array}$ & Folding degradation stability & $2.26 \pm 0.38$ & $1.77 \pm 0.09$ & $0.82 \pm 0.02$ & $\mathrm{~N} / \mathrm{A}$ \\
\hline SNXI & $\begin{array}{l}00198369 \\
0012544 \mid\end{array}$ & Transport & $2.21 \pm 0.6$ & $1.51 \pm 0.03$ & Not detected & Yes \\
\hline $\mathrm{SHH}$ & 00123314 & Signaling & $5.47 \pm 0.98$ & Low specificity & Low specificity & Yes \\
\hline VAMP3 & $\begin{array}{c}00 \mid 32276 \\
(002|097|)\end{array}$ & Transport & $0.34 \pm 0.07$ & $0.48 \pm 0.13$ & $1.16 \pm 0.15$ & N/A \\
\hline
\end{tabular}

\footnotetext{
*: Among the five candidate proteins, only antibodies against SHH and SNXI demonstrated enough sensitivity and specificity for
} immunocytochemistry. 


\section{Cytoplasm Mitochondria}
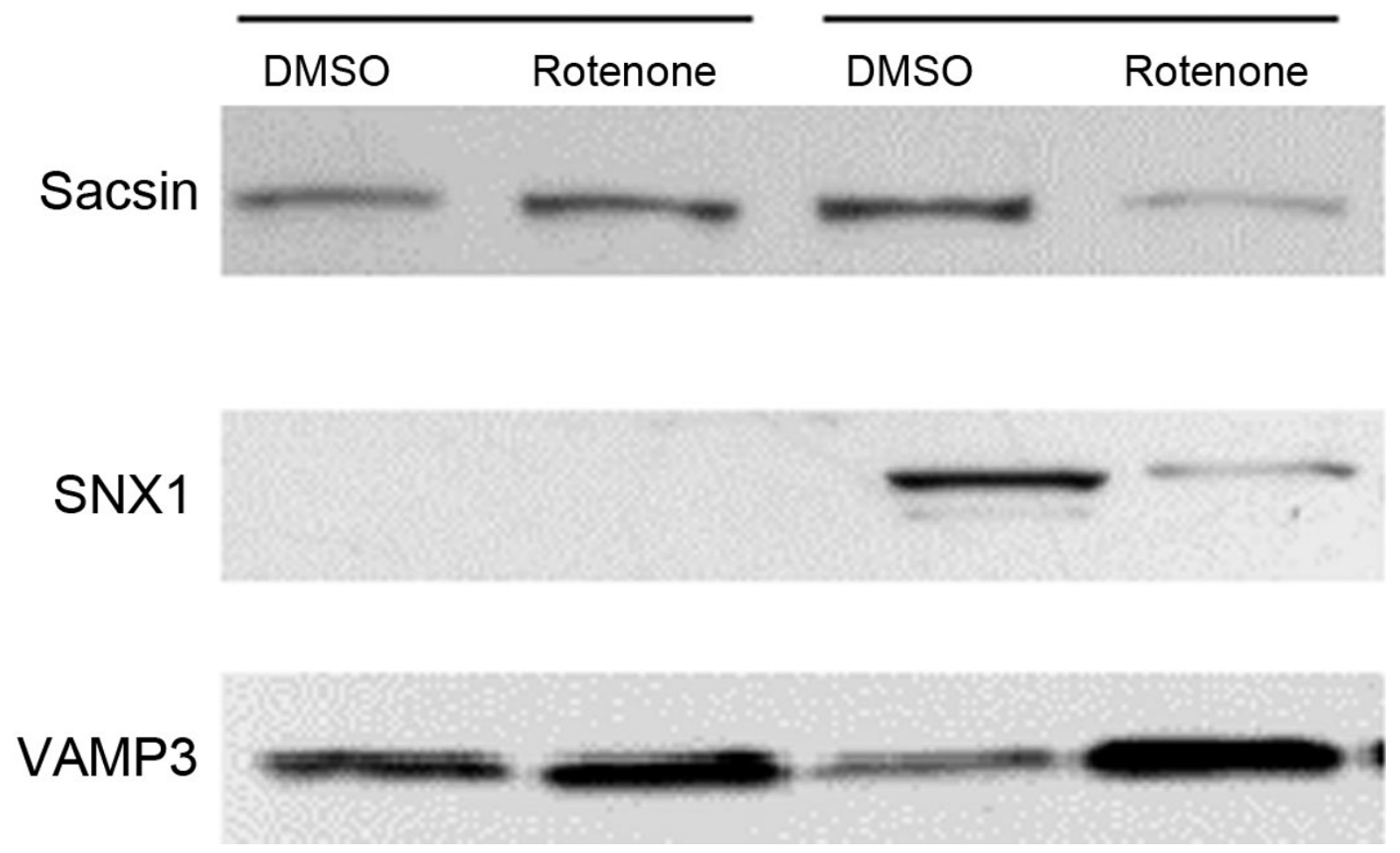

\section{Figure 4}

Validation of rotenone-affected mitochondrial proteins by WB. Purified mitochondria were isolated from MES cells treated with $20 \mathrm{nM}$ rotenone or vehicle (DMSO), respectively. Equal amounts of mitochondrial proteins (20 $\mu \mathrm{g})$ were loaded onto an $8-16 \%$ or $4-15 \%$ SDS-PAGE and analyzed by WB. The WB ratio in mitochondria and cytoplasm was calculated as DMSO/rotenone (D/R) from 3 batches of independent experiments and is shown in Table 2.

1) a total of 1722 proteins were identified as mitochondrial protein or mitochondria-associated proteins, which is the most comprehensive study of the mitochondrial proteome so far; 2) quantitative analysis of the mitochondrial protein profiles identified 311 proteins that displayed changes in relative abundance in MES cells treated with rotenone vs. controls. Among these, 110 proteins have been represented in the MitoP2 database as mitochondrial proteins; and 3) a subset of novel mitochondria-associated proteins affected by rotenone was validated by confocal microscopy and WB to assess their localization in the mitochondria as well as quantitative changes as determined by quantitative proteomics.

The first achievement of this study is the comprehensive survey of mitochondrial proteins in MES cells, a DAergic cell line widely used for the investigation of PD pathogen- esis [26,27]. Not only does extensive characterization of the mitochondrial proteome expand current knowledge regarding the profiles of mitochondrial proteins, it also supplies the necessary information to appropriately interpret the mechanisms of rotenone-induced mitochondrial dysfunction in PD. Comparing the results reported in the literature [25,28-30], the current analysis is a much deeper analysis into the mitochondrial proteome in a neuronal cell line, largely owing to better sample separation by SDS-PAGE and LC, i.e. extensive fractionation prior to MS analysis. This study, using only $80-100 \mu \mathrm{g}$ of mitochondrial proteins as the starting material, followed by simple LC-MS/MS analysis of 10 gel slices in two independent experiments, afforded the conclusive identification of 1864 proteins. Thus, this simple technology seems to be the most effective method of identifying a large number of proteins from different cell types. Furthermore, this is the 
first large-scale study where the mitochondrial proteome from the MES cell line was carefully characterized, providing organelle-specific proteomics information for these cells relevant to PD pathogenesis. Among those proteins identified, approximately 50\% did not have an apparent orthologue in the MitoP2 database. Several reasons are likely responsible for this absence in the database. First, the current database is still far from complete and most of the missing proteins are hypothetical proteins or proteins with unknown functions. Second, although the purification protocols for mitochondria have been refined by several groups over many years, the exquisite sensitivity of modern mass spectrometers has revealed that it is very difficult, if not impossible, to purify these or any other organelles to homogeneity. In our study, a small portion of those proteins $(7.5 \%)$ was considered as contaminated from cytoplasm, nucleus, ER, golgi or lysosome, based on the functional interpretation of SWISS-Prot database. While the sucrose gradient ultracentrifugation technique we used to isolate the mitochondrial fraction is widely recognized as the technique producing least contamination $[30,31]$, it remains likely that at least some of these proteins, particularly ER proteins, were co-localized in the mitochondrial fraction as contaminants. It is also possible that some of the "contaminating" proteins are partially localized in mitochondria or interact with other mitochondrial proteins. More detailed studies such as immuno-colocalization experiments would be required to distinguish these different possibilities.

Next, to better understand the mechanisms underlying mitochondrial dysfunction induced by rotenone, we used SILAC to compare the protein profiling of mitochondria in rotenone-treated MES cells versus controls. With SILAC methods, a total of 156 and 155 proteins showed significant increase or decrease after rotenone treatment. Among these, 53 and 57 proteins have been present in the MitoP2 database as mitochondrial proteins respectively. One of the major caveats of proteomics identification of proteins relates to the fact that proteins are inferred by the peptide sequence based on databases, which are currently incomplete. Thus, any given identification, with or without quantitative changes, should be considered provisional until it can be validated via alternative means. It is obviously impractical to validate the entire list of proteins listed in Additional file 1 or even Table 1; to this end, we validated five candidate proteins (sacsin, SNX1, VAMP3, MAP2K2 and SHH) in terms of their cellular location as well as quantitative alternation after rotenone treatment. Two of these proteins, SHH and SNX1, were co-localized to mitochondria convincingly by confocal investigation. Three of these proteins, SNX1, sacsin and VAMP3, when assessed by WB analysis, showed good agreement with our SILAC results. It should be noted that there are many caveats associated with $\mathrm{WB}$ and immnocytochemistry, such that a negative result by these assays does not necessarily negate what was observed by quantitative proteomics.

The biological importance of the three validated proteins in PD or rotenone pathogenesis is largely unknown. A potential role of sacsin has been implicated in an early onset neurodegenerative disorder, autosomal recessive spastic ataxia of Charlevoix-Saguenay (ARSACS), which occurs with a high prevalence in the Charlevoix-SaguenayLac-Saint-Jean (CSLSJ) region of Quebec [32]. Sacsin contains three regions with Hsp90 subdomains that have similarity to each other and the protein product of an Arabidopsis thaliana ORF. The presence of heat shock domains in the sacsin protein suggests its possible function in chaperone-mediated protein folding [32,33]. SNX1 is a protein that binds to the cytoplasmic domain of plasma membrane receptors [34]. It has been proposed to be associated with early endosomes and the regulation of endocytic trafficking of plasma membrane proteins in early endosomes such as epidermal growth factor receptor (EGFR) [35] and protease-activated receptor-1 (PAR1) [36]. VAMP3, an early endosomal vesicular soluble $\mathrm{N}$ ethylmaleimide-sensitive protein attachment protein receptor (v-SNARE), is a membrane trafficking protein of a constitutively recycling pathway [37]. Although neither SNX1 nor VAMP3 has been linked to PD pathogenesis thus far, it has been clearly demonstrated by others that dysfunctions of intracellular trafficking and lysosomal degradation are involved in PD pathogenesis $[38,39]$. Finally, it needs to be pointed out that this investigation is limited in that we have only compared the protein profiles in MES cells treated with rotenone for three days, when LB like inclusions are found [17]. It would be important in future experiments to examine earlier time points, revealing factors/pathways leading to cell death prior to formation of LB like inclusions.

\section{Conclusion}

In summary, we have employed SILAC, combined with 1D SDS-PAGE, to characterize numerous mitochondrial proteins in MES cells, representing the most extensive profiling study of mitochondrial proteins to date. Furthermore, we identified 110 mitochondrial proteins affected by rotenone. Finally, we have confirmed 2 of these proteins localizing in the mitochondria and quantitatively validated 3 of these proteins by WB. Detailed characterization of these rotenone-responsive novel proteins will likely facilitate a clearer understanding of PD pathogenesis.

\section{Methods \\ Reagents and antibodies}

All reagents were purchased from Sigma (St. Louis, MO) unless otherwise specified. Antibodies used included: 
mitochondrial marker anti-cytochrome C (BD Pharmigen, San Diego, CA); cytosolic marker anti- $\alpha$-tubulin (Abcam, Cambridge, MA); nuclear marker anti-nucleolin (Novus, Littleton, CO); novel mitochondrial proteins anti-sacsin (BD Pharmingen); anti-sorting nexin protein 1 (SNX1, Proteintech, Chicago, IL); anti-vesicles associated membrane protein 3 (VAMP3, Novus); anti-sonic hedgehog protein (SHH, GeneTex, San Antonio, TX); and antimitogen activated protein kinase kinase 2 (MAP2K2, Abgent, San Diego, CA).

\section{Cell culture and treatment}

A DAergic neuronal cell line, MES (a gift from Dr. Le at Baylor College of Medicine in Houston), was used in this study, which expresses most features of human DAergic neurons and has been widely used in PD-related experiments $[26,40,41]$. Detailed methods for culturing MES cells have been previously described by us [26]. In order to identify the potential mediators of mitochondrial dysfunction induced by rotenone, a newly developed quantitative proteomics technique termed SILAC was used [42]. Briefly, parallel MES cultures were grown in identical culture media except for one essential amino acid, L-arginine: the first media contained the "light" ( $\left.\mathrm{L}-\left[{ }^{12} \mathrm{C}_{6}\right] \mathrm{Arg}\right)$ (Cambridge Isotope Laboratories, Andover, MA) isotope and the other contained the "heavy" (L- $\left[{ }^{13} \mathrm{C}_{6}\right] \mathrm{Arg}$ ) isotope. After being cultured for at least five generations (to achieve near $100 \%$ incorporation of arginine [42]), L$\left[{ }^{13} \mathrm{C}_{6}\right]$ Arg- and L- $\left[{ }^{12} \mathrm{C}_{6}\right]$ Arg-labeled MES cells were treated with $20 \mathrm{nM}$ rotenone in DMSO or DMSO alone, respectively, for another 3 days.

\section{Mitochondrial Isolation and WB}

Mitochondria were isolated as described previously with minor modifications [28]. After treatment, equal amounts of L- $\left[{ }^{13} \mathrm{C}_{6}\right]$ Arg- and L- $\left[{ }^{12} \mathrm{C}_{6}\right]$ Arg-labeled MES cells were combined and collected by centrifugation at $260 \times g$ for $10 \mathrm{~min}$ at $4{ }^{\circ} \mathrm{C}$. The cell pellets were washed twice with icecold PBS (pH 7.4) and resuspended with 10 volumes of isolation buffer (20 mM HEPES-KOH, pH 7.5, $10 \mathrm{mM}$ $\mathrm{KCl}, 1.5 \mathrm{mM} \mathrm{MgCl} 2,1 \mathrm{mM}$ EDTA, $1 \mathrm{mM}$ EGTA, $1 \mathrm{mM}$ DTT, $0.25 \mathrm{M}$ sucrose, and a mixture of protease inhibitors). After 10-min incubation on ice, the cells were homogenized in a glass Dounce homogenizer (Wheaton, Milville, NJ). The homogenates were centrifuged twice at $650 \times g$ for $10 \mathrm{~min}$ at $4{ }^{\circ} \mathrm{C}$ to remove nuclei and unbroken cells. The postnuclear supernatants were centrifuged at $12,500 \times g$ for $25 \mathrm{~min}$ at $4^{\circ} \mathrm{C}$, and the pellets were resuspended carefully in mitochondrial isolation buffer and centrifuged again at $12,500 \times g$ for $25 \mathrm{~min}$. The heavy membrane fraction was then resuspended in isotonic sucrose buffer $(0.25 \mathrm{M}$ sucrose, $1 \mathrm{mM}$ EDTA, and $10 \mathrm{mM}$ Tris-HCl, pH 7.4), layered on a 1.0/1.5 M discontinuous sucrose gradient, and centrifuged at $60,000 \times g$ for $20 \mathrm{~min}$ at $4{ }^{\circ} \mathrm{C}$. The mitochondria collected from the phase between the 1.0 and $1.5 \mathrm{M}$ sucrose gradient were diluted in isolation buffer, and centrifuged again at $15,000 \times g$ for $20 \mathrm{~min}$ to pellet the mitochondria. Purified mitochondrial pellets were washed with isolation buffer, solubilized in RIPA buffer (50 mM Tris-HCl, pH 8.0, $150 \mathrm{mM}$ $\mathrm{NaCl}, \quad 0.1 \%$ NP-40, $0.05 \%$ SDS, $0.5 \%$ deoxycholate sodium, and a mixture of protease inhibitors) and centrifuged at $14,000 \times g$ for $10 \mathrm{~min}$. The supernatant was collected, and protein concentration was determined by a Micro-BCA protein concentration determination kit (Pierce, Rockford, IL). For WB, equal amounts of protein of various subcellular fractions were loaded in each lane of an $8-16 \%$ Tris/glycine/SDS gel (Bio-rad, Hercules, CA). After gel electrophoresis and protein transfer, the membranes were probed with various primary and corresponding secondary antibodies against marker proteins from different cellular compartments. Immunoreactivity was detected with an ECL method (PerkinElmer, Boston, MA).

\section{SDS-PAGE and in-gel digestion with trypsin}

A total of $100 \mu \mathrm{g}$ mitochondrial protein was loaded on an $8-16 \%$ Tris/glycine/SDS gel (Bio-rad) and run at $100 \mathrm{~V}$ for $10 \mathrm{~min}$, then $160 \mathrm{~V}$ for $1 \mathrm{~h}$. The gel was stained with Coomassie blue R-250 (50\% methanol, 10\% acetic acid, $0.1 \% \mathrm{R}-250$ ) for $1 \mathrm{~h}$ and destained overnight in a solution containing 5\% methanol/7\% acetic acid. After imaging, stained protein bands were cut into 10 fractions according to molecular weight and distribution of protein abundance, and each fraction was then excised into smaller pieces of approximately 1 to $2 \mathrm{~mm}^{3}$. The gel pieces were destained with $50 \%$ methanol $/ 5 \%$ acetic acid overnight, and in-gel digestion was performed as described previously [43]. The extracted peptides were desalted with a reverse-phase (RP) Atlantis dC18 column (Waters, Milford,

$\mathrm{MA})$.

\section{Protein identification by LC-MSIMS}

Desalted peptides from each fraction were further separated by a two-dimensional microcapillary high performance LC system, which integrates a strong cation-exchange (SCX) column $(100 \mathrm{~mm}$ in length $\times 0.32 \mathrm{~mm}$ for inner diameter; particle size: $5 \mu \mathrm{m}$ ) with two alternating RP C18 columns $(100 \mathrm{~mm}$ in length $\times 0.18 \mathrm{~mm}$ for inner diameter), followed by analysis of each peptide with MS/MS in a LCQ DECA PLUS XP ion trap (ThermoElectron, San Jose, CA). Settings for the LCMS/MS were the following: six fractions were eluted from SCX using a binary gradient of $2-90 \%$ solvent D (1.0 M ammonium chloride and $0.1 \%$ formic acid in $5 \%$ acetonitrile) versus solvent $\mathrm{C} \mathrm{(} 0.1 \%$ formic acid in 5\% acetonitrile). Each fraction was injected onto a RP column automatically with the peptides being resolved using a $300 \mathrm{~min}$ binary gradient of $5-80 \%$ solvent $B$ (acetonitrile and $0.1 \%$ formic acid) versus solvent A $(0.1 \%$ formic acid in water). A flow rate of $160 \mu \mathrm{l} / \mathrm{min}$ with a split ratio of $1 / 80$ was used. Peptides were eluted 
directly into the electrospray ionization (ESI) ion trap mass spectrometer capable of data-dependent acquisition. Each full MS scan was followed by two MS/MS scans of the two most intense peaks in the full MS spectrum with dynamic exclusion enabled to allow detection of lessabundant peptide ions. Mass spectrometric scan events and HPLC solvent gradients were controlled by the Xcalibur software (Thermo Finnigan).

\section{MSIMS data analysis}

Proteins from the mitochondrial fraction were later identified automatically using the computer program Sequest ${ }^{\mathrm{TM}}$, which searched the MS/MS spectra against the rat + mouse International Protein Index (IPI, v3.01, 43175 entries) database $[17,18,22,25,29]$. Search parameters for the SILAC-labeled samples used in this study were the following: +6 Da for ${ }^{13} \mathrm{C}$ isotopic-labeled arginine, +16 Da for oxidized methionine, +57 Da for carbamidomethyl; mass tolerance $\pm 3 \mathrm{Da}$. Potential peptides and proteins were further analyzed with PeptideProphet ${ }^{\mathrm{TM}}$ and ProteinProphet ${ }^{\mathrm{TM}}$ based on statistical models $[17,44,45]$. PeptideProphet uses various SEQUEST scores and a number of other parameters to calculate a probability score for each identified peptide. The peptides were then assigned a protein identification using the ProteinProphet software. ProteinProphet allows filtering of largescale data sets with assessment of predictable sensitivity and false-positive identification error rates. In our study, only proteins with a high probability of accuracy $(<5 \%$ error rate) were selected. Quantification of the ratio of each protein (isotopically light [control] vs heavy [roteonone treatment]) was calculated using the automated statistical analysis of protein abundance (ASAP) Ratio program [46] and expressed as average ratio \pm SE. All of these methods are used routinely in our lab $[17,18,22,25,29]$.

\section{Bioinformatics Analysis}

For prediction of the subcelluar location of proteins, all the proteins identified by MS/MS were searched against the Mouse Mitochondrial Proteome Database [47], which includes summarized results from computational predictions of signaling sequences, proteome mapping, mutant screening, expression profiling, protein-protein interactions and cellular sub-localization studies.

\section{Double immunofluorescent staining and confocal analysis of candidate proteins}

MES cells were seeded on chambered glass slides (Nalge Nunc, Naperville, IL), fixed in $4 \%$ paraformaldehyde followed by overnight incubation with primary antibodies to cytochrome $\mathrm{C}$ and one of the candidate proteins (SNX1 1:200, VAMP3 1:200, MAP2K2 1:200, SHH 1:200), followed by incubation with secondary antibody (1:200 Flex Fluor $^{\circledast} 488$ goat anti-mouse IgG and 1:200 Flex Fluor ${ }^{\circledast} 568$ goat anti-rabbit IgG or 1:200 Flex Fluor ${ }^{\circledast} 568$ donkey antigoat IgG, Molecular Probes, Eugene, OR). A laser scanning confocal microscope (Bio-Rad LS2000, Hercules, CA) was used to capture images.

\section{WB for validation of candidate mitochondrial proteins affected by rotenone}

MES cells were treated with $20 \mathrm{nM}$ rotenone or DMSO for 3 days, and mitochondria were isolated as for SILAC experiments described above. The relative intensity of the corresponding bands was quantified with Quantity One (Bio-Rad) and relative changes expressed as the ratio of DMSO-treated to rotenone-treated intensities. At least three independent experiments were performed for each candidate protein.

\section{Abbreviations}

LB, Lewy body; LC, Liquid chromatography; MAP2K2, Mitogen activated protein kinase kinase 2; MudPIT, Multidimensional protein identification technology; PD, Parkinson's disease; $\mathrm{SHH}$, Sonic hedgehog protein; SILAC, Stable isotope labeling by amino acids in cell culture; SNX1, Sorting nexin 1; VAMP3, Vesicle-associated membrane protein 3 ; WB, Western blotting.

\section{Authors' contributions}

$\mathrm{JJ}$ and JZ designed the research. JJ and ML carried out the mitochondrial isolation and proteomic identification. JJ and CP carried out the mass spectrometry analysis. JJ, DZ and DK performed proteomics data analysis and bioinformatics analysis. JJ and JD participated in the candidate proteins validation. JJ, KM and JZ participated in coordination and drafted the manuscript. All authors read and approved the final manuscript.

\section{Additional material}

\section{Additional file 1}

Total proteins/groups identified with $\geq 2$ peptides in mitochondria isolated from MES cells. The table shows total proteins/groups identified with $\geq 2$ peptides in mitochondria isolated from MES cells.

Click here for file

[http://www.biomedcentral.com/content/supplementary/14712202-8-67-S1.doc]

\section{Acknowledgements}

The study is supported by NIH grants to JZ (ROI AG025327 and ROIESOI2703).

\section{References}

I. Olanow CW, Obeso JA, Stocchi F: Continuous dopamine-receptor treatment of Parkinson's disease: scientific rationale and clinical implications. Lancet Neurol 2006, 5(8):677-687.

2. Lang AE, Miyasaki J, Olanow CW, Stoessl AJ, Suchowersky O: Progress in clinical neurosciences: a forum on the early man- 
agement of Parkinson's disease. The Canadian journal of neurological sciences 2005, 32(3):277-286.

3. Forno LS: The Lewy body in Parkinson's disease. Adv Neurol 1987, 45:35-43.

4. Gandhi S, Wood NW: Molecular pathogenesis of Parkinson's disease. Hum Mol Genet 2005, I 4(18):2749-2755

5. Hsu LJ, Sagara Y, Arroyo A, Rockenstein E, Sisk A, Mallory M, Wong J, Takenouchi T, Hashimoto M, Masliah E: alpha-synuclein promotes mitochondrial deficit and oxidative stress. Am J Pathol 2000, I 57(2):40I-4I0.

6. Schapira AH, Cooper JM, Dexter D, Clark JB, Jenner P, Marsden CD: Mitochondrial complex I deficiency in Parkinson's disease. Journal of neurochemistry 1990, 54(3):823-827.

7. Schapira AH: Mitochondrial complex I deficiency in Parkinson's disease. Adv Neurol 1993, 60:288-291.

8. Beal MF: Mitochondria, oxidative damage, and inflammation in Parkinson's disease. Ann N Y Acad Sci 2003, 99 I: | 20-131.

9. Langston JW, Langston EB, Irwin I: MPTP-induced parkinsonism in human and non-human primates--clinical and experimental aspects. Acta Neurol Scand Suppl 1984, 100:49-54.

10. Turrens JF, Boveris A: Generation of superoxide anion by the NADH dehydrogenase of bovine heart mitochondria. Biochem J 1980, 191(2):42I-427.

II. Betarbet R, Sherer TB, MacKenzie G, Garcia-Osuna M, Panov AV, Greenamyre JT: Chronic systemic pesticide exposure reproduces features of Parkinson's disease. Nat Neurosci 2000 , 3(12): $130 \mid-1306$.

12. Ryu EJ, Harding HP, Angelastro JM, Vitolo OV, Ron D, Greene LA: Endoplasmic reticulum stress and the unfolded protein response in cellular models of Parkinson's disease. J Neurosci 2002, 22(24): 10690-10698.

13. Sherer TB, Betarbet R, Stout AK, Lund S, Baptista M, Panov AV, Cookson MR, Greenamyre JT: An in vitro model of Parkinson's disease: linking mitochondrial impairment to altered alphasynuclein metabolism and oxidative damage. J Neurosci 2002 , 22(16):7006-7015.

14. Ahmadi FA, Linseman DA, Grammatopoulos TN, Jones SM, Bouchard RJ, Freed CR, Heidenreich KA, Zawada WM: The pesticide rotenone induces caspase-3-mediated apoptosis in ventral mesencephalic dopaminergic neurons. I Neurochem 2003, 87(4):9|4-92I.

15. Moon Y, Lee KH, Park JH, Geum D, Kim K: Mitochondrial membrane depolarization and the selective death of dopaminergic neurons by rotenone: protective effect of coenzyme Q 10 . J Neurochem 2005, 93(5): I 199-1 208.

16. Zoccarato F, Toscano P, Alexandre A: Dopamine-derived dopaminochrome promotes $\mathrm{H}(2) \mathrm{O}(2)$ release at mitochondrial complex I: stimulation by rotenone, control by $\mathbf{C a}(2+)$, and relevance to Parkinson disease. J Biol Chem 2005, 280(16): I5587-15594.

17. Zhou Y, Gu G, Goodlett DR, Zhang T, Pan C, Montine TJ, Montine $\mathrm{KS}$, Aebersold RH, Zhang J: Analysis of alpha -synuclein-associated proteins by quantitative proteomics. The Journal of biological chemistry 2004, 279(37):39|55-39164.

18. Jin J, Li GJ, Davis J, Zhu D, Wang Y, Pan C, Zhang J: Identification of novel proteins associated with both alpha-synuclein and DJI. Mol Cell Proteomics 2007, 6(5):845-859.

19. Xu J, Zhong N, Wang H, Elias JE, Kim CY, Woldman I, Pifl C, Gygi SP, Geula C, Yankner BA: The Parkinson's disease-associated DJ-I protein is a transcriptional co-activator that protects against neuronal apoptosis. Hum Mol Genet 2005, 14(9): $123 \mid-1241$.

20. Thiede B, Kretschmer A, Rudel T: Quantitative proteome analysis of CD95 (Fas/Apo-I)-induced apoptosis by stable isotope labeling with amino acids in cell culture, 2-DE and MALDIMS. Proteomics 2006, 6(2):614-622.

21. Washburn MP, Wolters D, Yates JR 3rd: Large-scale analysis of the yeast proteome by multidimensional protein identification technology. Nat Biotechnol 200I, 19(3):242-247.

22. Zhou $Y$, Wang $Y$, Kovacs M, Jin J, Zhang J: Microglial activation induced by neurodegeneration: a proteomic analysis. Mol Cell Proteomics 2005, 4(10): I 47I-I479.

23. Hamosh A, Scott AF, Amberger JS, Bocchini CA, McKusick VA: Online Mendelian Inheritance in Man (OMIM), a knowledgebase of human genes and genetic disorders. Nucleic Acids Res 2005, 33(Database issue):D5|4-7.
24. Bove J, Prou D, Perier C, Przedborski S: Toxin-induced models of Parkinson's disease. NeuroRx 2005, 2(3):484-494.

25. Jin J, Hulette C, Wang Y, Zhang T, Pan C, Wadhwa R, Zhang J: Proteomic identification of a stress protein, mortalin/mthsp70/ GRP75: relevance to Parkinson disease. Mol Cell Proteomics 2006, 5(7): I 193-1 204.

26. Zhang J, Kravtsov V, Amarnath V, Picklo MJ, Graham DG, Montine T] Enhancement of dopaminergic neurotoxicity by the mercapturate of dopamine: relevance to Parkinson's disease. Journal of neurochemistry 2000, 74(3):970-978.

27. Sharon R, Bar-Joseph I, Frosch MP, Walsh DM, Hamilton JA, Selkoe DI: The formation of highly soluble oligomers of alpha-synuclein is regulated by fatty acids and enhanced in Parkinson's disease. Neuron 2003, 37(4):583-595.

28. Rezaul K, Wu L, Mayya V, Hwang SI, Han D: A systematic characterization of mitochondrial proteome from human $\mathrm{T}$ leukemia cells. Mol Cell Proteomics 2005, 4(2):169-18I.

29. Jin J, Meredith GE, Chen L, Zhou Y, Xu J, Shie FS, Lockhart P, Zhang J: Quantitative proteomic analysis of mitochondrial proteins: relevance to Lewy body formation and Parkinson's disease. Brain Res Mol Brain Res 2005, I34(I): I 19-138.

30. Taylor SW, Fahy E, Zhang B, Glenn GM, Warnock DE, Wiley S, Murphy AN, Gaucher SP, Capaldi RA, Gibson BW, Ghosh SS: Characterization of the human heart mitochondrial proteome. Nat Biotechnol 2003, 2 I (3):28I-286.

31. Jiang XS, Zhou H, Zhang L, Sheng QH, Li SJ, Li L, Hao P, Li YX, Xia QC, Wu JR, Zeng R: A high-throughput approach for subcellular proteome: identification of rat liver proteins using subcellular fractionation coupled with two-dimensional liquid chromatography tandem mass spectrometry and bioinformatic analysis. Mol Cell Proteomics 2004, 3(5):44I-455.

32. Engert JC, Berube P, Mercier J, Dore C, Lepage P, Ge B, Bouchard JP, Mathieu J, Melancon SB, Schalling M, Lander ES, Morgan K, Hudson TJ, Richter A: ARSACS, a spastic ataxia common in northeastern Quebec, is caused by mutations in a new gene encoding an II.5-kb ORF. Nat Genet 2000, 24(2): I20-I25.

33. Engert JC, Dore C, Mercier J, Ge B, Betard C, Rioux JD, Owen C Berube P, Devon K, Birren B, Melancon SB, Morgan K, Hudson TJ, Richter A: Autosomal recessive spastic ataxia of CharlevoixSaguenay (ARSACS): high-resolution physical and transcript map of the candidate region in chromosome region $13 \mathrm{qI} I$. Genomics 1999, 62(2): I56-164.

34. Nakamura N, Sun-Wada GH, Yamamoto A, Wada Y, Futai M: Association of mouse sorting nexin I with early endosomes. J Biochem (Tokyo) 200I, I 30(6):765-77I.

35. Kurten RC, Cadena DL, Gill GN: Enhanced degradation of EGF receptors by a sorting nexin, SNXI. Science 1996, 272(5264): $1008-1010$.

36. Gullapalli A, Wolfe BL, Griffin CT, Magnuson T, Trejo J: An essential role for SNXI in lysosomal sorting of protease-activated receptor-I: evidence for retromer-, Hrs-, and Tsg I0I-independent functions of sorting nexins. Mol Biol Cell 2006, 17(3): $1228-1238$

37. Proux-Gillardeaux $V$, Rudge $R$, Galli $T$ : The tetanus neurotoxinsensitive and insensitive routes to and from the plasma membrane: fast and slow pathways? Traffic 2005, 6(5):366-373.

38. Dalfo E, Gomez-Isla T, Rosa JL, Nieto Bodelon M, Cuadrado Tejedor M, Barrachina M, Ambrosio S, Ferrer I: Abnormal alpha-synuclein interactions with Rab proteins in alpha-synuclein A30P transgenic mice. J Neuropathol Exp Neurol 2004, 63(4):302-3I3.

39. Meredith GE, Totterdell S, Petroske E, Santa Cruz K, Callison RC Jr., Lau YS: Lysosomal malfunction accompanies alpha-synuclein aggregation in a progressive mouse model of Parkinson's disease. Brain Res 2002, 956(I): $156-165$.

40. Crawford GC, Le WD, Smith RG, Xie WJ, Stefani E, Appel SH: A novel NI8TG2 x mesencephalon cell hybrid expresss properties that suggest a dopaminergic cell line of substantia nigra origin. J Neurosci 1992, I 2(9):3392-3398.

4I. Zhang J, Price JO, Graham DG, Montine TJ: Secondary excitotoxicity contributes to dopamine-induced apoptosis of dopaminergic neuronal cultures. Biochem Biophys Res Commun 1998, 248(3):8|2-816.

42. Ong SE, Blagoev B, Kratchmarova I, Kristensen DB, Steen H, Pandey A, Mann M: Stable isotope labeling by amino acids in cell culture, SILAC, as a simple and accurate approach to expression proteomics. Mol Cell Proteomics 2002, I(5):376-386. 
43. Zhou Y, Shie FS, Piccardo P, Montine TJ, Zhang J: Proteasomal inhibition induced by manganese ethylene-bis-dithiocarbamate: relevance to Parkinson's disease. Neuroscience 2004, I 28(2):28I-29|.

44. Keller A, Nesvizhskii Al, Kolker E, Aebersold R: Empirical statistical model to estimate the accuracy of peptide identifications made by MS/MS and database search. Anal Chem 2002 74(20):5383-5392.

45. Keller A, Purvine S, Nesvizhskii Al, Stolyar S, Goodlett DR, Kolker E: Experimental protein mixture for validating tandem mass spectral analysis. Omics 2002, 6(2):207-2I2.

46. Li XJ, Zhang H, Ranish JA, Aebersold R: Automated statistical analysis of protein abundance ratios from data generated by stable-isotope dilution and tandem mass spectrometry. Anal Chem 2003, 75(23):6648-6657.

47. Mouse Mitochondrial Proteome Database [http:// www.mitop2.de]

48. Orth $\mathrm{M}$, Schapira $\mathrm{AH}$ : Mitochondria and degenerative disorders. Am J Med Genet 200I, I 06(I):27-36.

49. de Bernardo S, Canals S, Casarejos MJ, Solano RM, Menendez J, Mena $M A$ : Role of extracellular signal-regulated protein kinase in neuronal cell death induced by glutathione depletion in neuron/glia mesencephalic cultures. I Neurochem 2004 $91(3): 667-682$.

50. Li C, Wright MM, Jackson RM: Reactive species mediated injury of human lung epithelial cells after hypoxia-reoxygenation. Exp Lung Res 2002, 28(5):373-389.

5I. Mantovani M, Van Velthoven V, Fuellgraf H, Feuerstein TJ, Moser A: Neuronal electrical high frequency stimulation enhances GABA outflow from human neocortical slices. Neurochem Int 2006, 49(4):347-350.

52. Lockhart PJ, Holtom B, Lincoln S, Hussey J, Zimprich A, Gasser T, Wszolek ZK, Hardy J, Farrer MJ: The human sideroflexin 5 (SFXN5) gene: sequence, expression analysis and exclusion as a candidate for PARK3. Gene 2002, 285(I-2):229-237.

53. Liu JQ, Odani M, Yasuoka T, Dairi T, Itoh N, Kataoka M, Shimizu S, Yamada $\mathrm{H}$ : Gene cloning and overproduction of low-specificity D-threonine aldolase from Alcaligenes xylosoxidans and its application for production of a key intermediate for parkinsonism drug. Appl Microbiol Biotechnol 2000, 54(I):44-5I.

54. Ho HK, Jia Y, Coe KJ, Gao Q, Doneanu CE, Hu Z, Bammler TK, Beyer RP, Fausto N, Bruschi SA, Nelson SD: Cytosolic heat shock proteins and heme oxygenase-I are preferentially induced in response to specific and localized intramitochondrial damage by tetrafluoroethylcysteine. Biochem Pharmacol 2006, 72(1):80-90.

55. Schonfeld C, Wobbe L, Borgstadt R, Kienast A, Nixon PJ, Kruse O: The nucleus-encoded protein $\mathrm{MOCl}$ is essential for mitochondrial light acclimation in Chlamydomonas reinhardtii. J Biol Chem 2004, 279(48):50366-50374.

56. Park CH, Minn YK, Lee JY, Choi DH, Chang MY, Shim JW, Ko JY, Koh HC, Kang MJ, Kang JS, Rhie DJ, Lee YS, Son H, Moon SY, Kim KS, Lee $\mathrm{SH}$ : In vitro and in vivo analyses of human embryonic stem cell-derived dopamine neurons. I Neurochem 2005 92(5): $1265-1276$.

57. Zabel C, Sagi D, Kaind AM, Steireif N, Klare Y, Mao L, Peters H, Wacker MA, Kleene R, Klose J: Comparative proteomics in neurodegenerative and non-neurodegenerative diseases suggest nodal point proteins in regulatory networking. J Proteome Res 2006, 5(8): 1948-1958.

58. Pirim I: Production of anti-polyubiquitin and anti-ubiquitin carboxyl terminal hydrolase antibodies and immunohistochemically assessment of them on brain sections of Alzheimer's disease and Lewy body disease. Int J Neurosci I 998, 95( I2):33-42

59. Olanow CW, Tatton WG: Etiology and pathogenesis of Parkinson's disease. Annu Rev Neurosci 1999, 22: 123-|44.

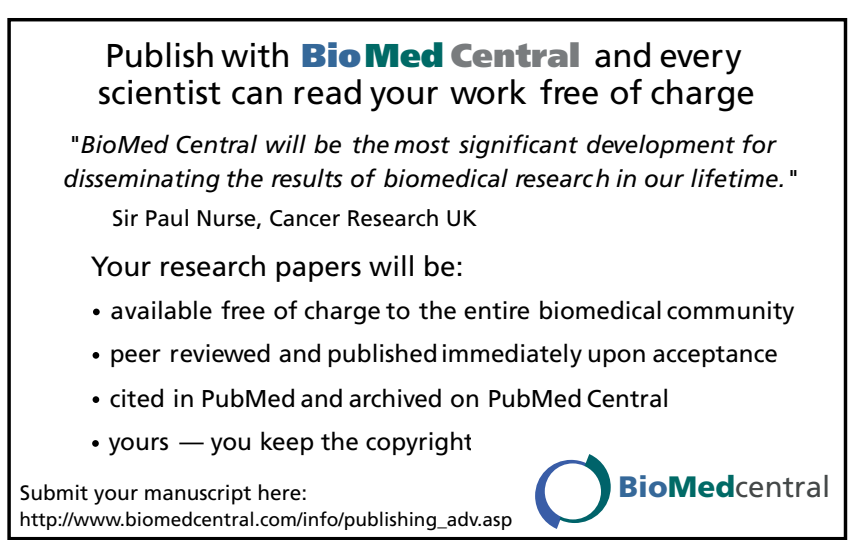

